ISSN 1518-3483

Licenciado sob uma Licença Creative Commons

\title{
Formação para o magistério: o discurso dos formadores ${ }^{1}$
}

\section{Teachers' formation: the discourse of the formators}

\begin{abstract}
Alda Judith Alves-Mazzotti
Ph.D, New York University, Universidade Estácio de Sá, Programa de Pós-Graduação em Educação, Rio de Janeiro, RJ - Brasil, e-mail: aldamazzotti@uol.com.br
\end{abstract}

\section{Resumo}

A formação de professores para as primeiras séries tem sido, na última década, objeto de extenso debate, no qual se observam controvérsias teóricas, ambiguidades normativas, bem como ampla diversidade nos currículos implementados pelas universidades. Diante desse cenário consideramos relevante investigar como professores de cursos de Pedagogia, responsáveis pela formação daqueles docentes, representam esse processo. A opção pelo referencial das representações sociais se deve ao fato de que estas têm por funções contribuir para a construção de uma realidade comum a um conjunto social e orientar e justificar as práticas dos sujeitos que o compõem. Os dados foram coletados por meio de um teste de livre evocação com justificativas, aplicado a 51 docentes de Pedagogia, e 15 entrevistas de aprofundamento. Os professores, no geral, apresentaram um discurso fragmentado, pontilhado por expressões retiradas da literatura corrente, sem, contudo, conseguir costurar uma imagem coerente do que seria

\footnotetext{
1 Pesquisa financiada pelo CNPq.
} 
a formação para o magistério. Entre essas expressões destaca-se professor reflexivo, aparentemente usada mais como um jargão do que como um conceito bem assimilado. Esses resultados nos levaram a questionar a existência de uma representação de formação para o magistério entre esses professores, parecendo que eles têm apenas opiniões, ou mesmo atitudes, mas não uma representação estruturada. Considerou-se que a existência de duas racionalidades em disputa, tanto nas discussões relativas às Diretrizes Curriculares para o Curso de Pedagogia como na literatura sobre formação do professor, tenha contribuído para a dispersão observada nas respostas ao teste de associação e nas entrevistas.

Palavras-chave: Representações sociais. Formação de professores. Diretrizes curriculares. Curso de Pedagogia. Professor reflexivo.

\begin{abstract}
In the last decade, the formation of teachers for the first grades has been object of an extensive debate, in which we could observe theoretical controversies, normative ambiguities, as well as a wide variety of curricula implemented by the universities. Given this scenery we considered relevant to investigate how teachers of university courses of Education, that is, the responsible for the formation of those teachers represent this process. The option for the theoretical-methodological referential of the social representations is due to the fact that they have the function of contributing to the construction of a common reality to a social set and to orientate and justify practices of the subjects that compose it. Data was collected through a test of free evocation with justification applied to 51 teachers of the Education course and 15 interviews. The teachers, in general, presented a fragmented discourse, full of expressions taken from the current literature, without being able to give a coherent image of what would be teacher formation. Among these expressions, reflexive teacher is the most frequent, apparently used as a jargon rather than as a well-assimilated concept. These results lead us to question the existence of a representation of teacher formation among these teachers, suggesting that they only have opinions, or even attitudes, but not a structured representation. It was considered that the existence of two rationalities in dispute, in the discussions related to the Curricular Guidelines for the Education course, as well as in the literature
\end{abstract}


about teacher formation, contributed for the dispersion observed in the answers to the association test and in the interviews.

Keywords: Social representations. Teacher formation. Curricular guidelines. Education course. Reflexive teacher.

\section{Introdução}

A formação de professores em cursos específicos se inicia, no Brasil, ao fim do século XIX, quando foram criadas as Escolas Normais para formar docentes para as "primeiras letras". Já os cursos de formação de professores para o "secundário" (que correspondia ao atual segundo segmento do ensino fundamental e ao ensino médio) só iriam surgir na década de 30 do século XX, com a criação das universidades, acoplando-se, aos três anos de bacharelado, um ano de formação pedagógica para a obtenção da licenciatura. Esse modelo, que ficou conhecido como 3+1, foi também aplicado ao curso de Pedagogia, regulamentado em 1939, que se destinava a formar especialistas em educação e docentes para as Escolas Normais. Instituía-se, assim, a diferenciação entre o professor polivalente, para o ensino das primeiras séries, e o professor especialista, para as demais séries, uma distinção que se evidencia até hoje nas carreiras, nas jornadas de trabalho, nos salários e também nas representações da sociedade, dos formuladores de políticas e dos próprios professores desses dois níveis de ensino (ALVES-MAZZOTTI, 2008; GATTI; BARRETTO, 2009).

A persistência dessa diferenciação, que constitui um obstáculo a qualquer inovação na estrutura curricular dos cursos de formação, levou Aguiar e Sheibe (2010) a destacarem, entre os desafios a serem enfrentados pelo novo Plano Nacional de Educação (PNE 2011/2020), a necessidade de sua superação. Outro desafio apontado por essas autoras é o distanciamento entre teoria e prática, bem como a prevalência da formação teórica nas áreas específicas sobre a prática, um problema cujas raízes 
parecem também remontar ao esquema $3+1$, uma vez que, nesse modelo, os três primeiros anos são reservados às disciplinas de conteúdo da área de especialidade, deixando-se o último ano para "o curso de didática".

Não cabe aqui detalhar toda a história da formação de professores em nosso País, mas é importante assinalar que o processo de profissionalização do magistério já se inicia assentado em bases polêmicas, refletindo vieses ideológicos prevalentes à época, destacando-se aí as representações da própria educação escolar, do papel da professora das "primeiras letras" e dos professores dos demais níveis de ensino. Essa trajetória permanece, até os nossos dias, pontuada por embates e dissensos decorrentes de conflitos entre valores, interesses e concepções de grupos diversos, em particular entre o governo e o movimento docente.

A Lei 9.394/96, de Diretrizes e Bases da Educação Nacional (LDB/96), que estabeleceu a exigência de nível superior para todos os professores da educação básica, se de um lado atendia aos anseios pela elevação do status profissional dos professores da educação infantil e das séries iniciais do ensino fundamental com a elevação de seu nível de formação, de outro criava uma nova polêmica, ao situá-la nos Institutos Superiores de Educação (ISE), e não nos cursos de Pedagogia. Em suas disposições transitórias, a lei fixava um prazo de dez anos para que os sistemas de ensino fizessem a adequação às novas normas, mas as primeiras adaptações de currículo só se iniciariam em 2002, com a promulgação das Diretrizes Curriculares Nacionais (DCN) para a Formação de Professores, estendendo-se aos anos seguintes, quando diretrizes para cada curso de licenciatura começaram a ser aprovadas (GATTI; BARRETTO, 2009).

O intervalo entre a promulgação da LDB/96 e a aprovação das DCN para o curso de Pedagogia, em 2006, foi marcado por uma acirrada disputa entre os favoráveis aos ISE e os grupos que defendiam a formação professores da educação infantil e das séries iniciais do ensino fundamental a ser feita no curso de Pedagogia. Aguiar et al. (2006) recuperam esse debate, apontando, como marco importante o ano de 1998, quando a Comissão de Especialistas, instituída para elaborar as diretrizes do curso de Pedagogia, desencadeou um amplo processo de discussão, em nível 
nacional, ouvindo as coordenações de curso e as entidades representativas de professores, pesquisadores e estudantes de Pedagogia. Desse processo resultou a elaboração das Diretrizes Curriculares Nacionais para o curso de Pedagogia, encaminhadas ao Conselho Nacional de Educação (CNE) em maio de 1999, que permaneceram por oito anos aguardando a decisão sobre os pontos polêmicos. Finalmente, em 2006, o CNE, depois de longo debate, aprovou as Diretrizes Curriculares Nacionais para os cursos de graduação em Pedagogia, licenciatura (Resolução n. 1 de 15/5/06), acrescentando a esses cursos a atribuição de formar professores para a educação infantil e para as séries iniciais do ensino fundamental, o que não estava previsto na LDB. As ambiguidades presentes na forma final do documento e o caráter ao mesmo tempo restrito e extensivo, o que caracteriza as atuais Diretrizes, refletem a negociação entre os interesses diversificados presentes no processo de sua elaboração (SHEIBE; DURLI, 2010).

Para Aguiar et al. (2006), apesar de a formação de professores, e em particular o curso de Pedagogia, terem sido discutidos em diferentes fóruns, não se chegou sequer a algo próximo de um consenso sobre aspectos essenciais, como os objetivos do curso, a proposta curricular adequada ao alcance desses objetivos e o próprio estatuto epistemológico do campo da Pedagogia. Para esses autores, as várias iniciativas do MEC com relação à formação de professores e ao próprio curso de Pedagogia causaram mais transtornos do que encaminhamentos positivos, favorecendo o surgimento de uma diversidade de estruturas curriculares que exigirá do Poder Público um acompanhamento rigoroso, com avaliação sistemática da formação oferecida.

De fato, estudos conduzidos por Gatti e Nunes em 2008 (apud GATTI; BARRETTO, 2009), que analisaram currículos de 71 cursos de Pedagogia de todo o País, encontraram 3.513 disciplinas diferentes, sendo 3.107 obrigatórias e 406 optativas. A análise dos currículos indicou que estes eram bastante fragmentados, o que foi confirmado pelo exame do projeto pedagógico, no qual não são identificadas articulações entre as disciplinas. Os projetos e as ementas não informam como os estágios 
são realizados e supervisionados e não deixam claros seus objetivos nem como devem se integrar com as disciplinas formativas. Além disso, em sua maioria, envolvem atividades de observação, não constituindo, portanto, práticas efetivas. As autoras observam ainda que, embora aparentemente haja uma razoável equivalência entre a proporção de disciplinas de embasamento teórico nas diferentes áreas de conhecimento e as destinadas à formação profissional específica do professor, uma análise mais acurada permite perceber que, mesmo nessas disciplinas, também predominam enfoques que buscam fundamentar os conhecimentos focalizados, mas pouco exploram seus desdobramentos em termos das práticas educacionais. Assim, a complexa mediação entre teoria e prática parece, de fato, não se realizar.

Em resumo, a normatização relativa à formação de professores é um emaranhado de diretrizes, resoluções, portarias, pareceres que mais confundem do que esclarecem gestores e professores responsáveis por sua implementação a respeito do que e como fazer.

Outra forma de buscar compreender os caminhos que estão sendo propostos para os cursos de formação para o magistério seria a análise da literatura acadêmica sobre os chamados saberes docentes, que parece ter tido papel importante na fundamentação das reformas dos anos 1990. Segundo Borges e Tardif (2001), as mudanças realizadas no Brasil se inscrevem no contexto mais amplo das reformas no plano internacional, nas quais podem ser identificados alguns princípios comuns, entre os quais destacamos:

a) conceber o ensino como uma atividade profissional de alto nível que se apoia em um sólido repertório de conhecimentos;

b) ver os professores como 'práticos reflexivos', capazes de produzir saberes específicos ao seu próprio trabalho e deliberar sobre suas práticas, refletindo sobre elas, compartilhando-as e as aperfeiçoando de modo a aumentar sua eficácia;

c) ver a prática profissional como lócus de formação e de produção de saberes. 
Esses autores chamam a atenção para o fato de que essas reformas propõem profundas mudanças no modelo de formação em vigor nas universidades, uma vez que, mais que os conteúdos, disciplinas e pesquisas universitárias, seriam os saberes da ação as práticas profissionais que constituiriam o quadro de referência da nova formação dos professores.

A crítica à racionalidade técnica que prevalecia até então - na qual a teoria é compreendida como um conjunto de conhecimentos produzidos pelas ciências da educação e a prática como a aplicação da teoria e das técnicas - está na base dos movimentos de reforma. A nova maneira de ver a formação e os saberes docentes propõe uma racionalidade prática, valorizando a reflexão sobre e na ação docente. Essa posição é defendida por autores como Schön, Zeichner, Shulman, Gauthier, Nóvoa, Tardif e Perrenoud, entre outros, e embora receba várias denominações, pode ser identificada pela expressão "professor reflexivo" (GUIMARÃES, 2010, p. 38).

Saudado inicialmente com entusiasmo por muitos pesquisadores brasileiros como uma alternativa promissora para o desenvolvimento profissional dos professores, esse modelo formativo começa a ser severamente criticado. Alves (2007) examina esse debate destacando o fato de que os principais questionamentos consideram que as reformas, bem como os autores em que se basearam, estão vinculadas às perspectivas neoliberais. Freitas (2002), por exemplo, ao analisar os embates sobre as Diretrizes Curriculares, afirma que a desresponsabilização do Estado e o sentido instrumental da política de formação docente no País, ao enfatizar os saberes da prática, estariam privando os professores da formação científica e acadêmica necessária à sua profissionalização. Também preocupada com a preservação da dimensão teórica na formação do professor, Pimenta (2002) afirma que diversos autores têm alertado para um possível 'praticismo' decorrente do protagonismo do professor na construção do saber docente; de um possível 'individualismo', fruto de uma reflexão em torno de si próprio; e de uma possível hegemonia autoritária, ao considerar que a perspectiva da reflexão é suficiente para a resolução dos problemas da prática. 
Dias da Silva (2005, p. 300) também concorda que as reformas efetivadas no Brasil, orientadas pela perspectiva dos saberes docentes, vêm consolidando um projeto educacional de cunho neoliberal, em que um Estado mínimo se desobriga de suas responsabilidades e promove o barateamento da formação das novas gerações. Afirma a autora:

em nome da valorização dos saberes docentes e do enfrentamento da dicotomia teoria-prática, talvez a própria área de educação possa estar contribuindo para a desprofissionalização dos professores apostando que sua formação seja essencialmente "prática" [...]. É preciso reconhecer que não são raros os projetos e discursos que, justificados pelo argumento da formação de um professor "prático reflexivo", que deve "refletir sobre seu trabalho e suas concepções", estão transformando a formação de professores em feiras de vivências pessoais partilhadas.

Concluindo, parece claro que o campo dos saberes docentes também não representa uma sólida referência para orientar os cursos de formação para o magistério. Nesse cenário no qual se mesclam controvérsias teóricas, ambiguidades normativas e diversidade de matrizes curriculares implementadas pelas universidades, torna-se relevante investigar como professores responsáveis pela formação se situam diante dessa missão.

Assim, a pesquisa aqui apresentada buscou conhecer as representações sociais de formação para o magistério elaboradas por professores de cursos de Pedagogia, ou seja, por formadores de professores para a educação infantil e as séries iniciais do ensino fundamental. A opção pela Teoria das Representações Sociais (MOSCOVICI, 1978; ABRIC, 1994, $1998,2003)$ se deve ao fato de que estas têm por funções contribuir para a construção de uma realidade comum a um conjunto social e orientar e justificar as práticas dos sujeitos que o compõem. Nesse sentido, nos indicam o que é a formação para o magistério para os professores do curso de Pedagogia, ajudando-nos a compreender as crenças, valores e atitudes que possivelmente orientam sua prática docente. 


\section{Referencial teórico}

O conceito de representação social introduzido por Moscovici (1978) pode ser definido como uma forma específica de conhecimento, socialmente elaborado e partilhado, que nos ajuda a apreender os acontecimentos da vida cotidiana, a dominar o ambiente, a facilitar a comunicação de fatos e ideias e a nos situar diante de pessoas e grupos, orientando e justificando nosso comportamento. Diz-se que esse conhecimento é socialmente elaborado porque, embora se constitua a partir de nossa experiência pessoal, serve-se de informações, crenças, valores e modelos de pensamento que recebemos e transmitimos por meio da tradição, da educação e da comunicação social (JODELET, 2001).

Entre os desdobramentos atuais da teoria, destaca-se a abordagem estrutural das representações proposta por Jean Claude Abric. Na perspectiva de Abric (1994), a representação é vista como um sistema sociocognitivo particular composto de dois subsistemas: o núcleo central e o sistema periférico. O núcleo central é a base comum, consensual, da representação, aquela que resulta da memória coletiva e do sistema de normas do grupo. Constituído por um número bastante reduzido de elementos, ele é responsável pelo significado e pela organização interna da representação e também por sua estabilidade, resistindo às mudanças e assegurando, assim, a permanência da representação. Já o sistema periférico, formado pelos demais elementos da representação, é dotado de grande flexibilidade, constituindo a interface entre o núcleo central e a realidade imediata. Ao permitir a adaptação de seus elementos às mudanças nas situações concretas, protege-se o núcleo central, contribuindo para manter sua estabilidade.

Outra questão aprofundada por Abric, e que apresenta especial relevância para o nosso estudo, é aquela que focaliza especificamente as relações entre representações e práticas sociais. Ao analisar essa questão, Abric (1994, p. 217) lembra inicialmente que o termo prática não pode ser aplicado a comportamentos atomizados, propondo que 
se entenda práticas sociais como "sistemas de ação socialmente estruturados e instituídos com relação a papéis”, o que faz com que essa abordagem seja especialmente adequada ao levantamento de pistas sobre o papel que formadores de professores de educação infantil e de séries iniciais do ensino fundamental atribuem à formação pela qual são responsáveis.

Abric (1998) esclarece, ainda, que embora alguns autores enfatizem a influência das representações sobre as práticas, e outros, o inverso, a ideia de que representações e práticas se engendram mutuamente é hoje francamente hegemônica. Não se trata, porém, de simples reciprocidade. Com base em estudos empíricos, Abric (1998, p. 43) conclui que as representações devem ser vistas "como uma condição das práticas e as práticas como um agente de transformação das representações”.

\section{Metodologia}

A coleta de dados foi feita por meio de um teste de livre evocação de palavras com justificativas, aplicado a 51 docentes de Pedagogia, e 15 entrevistas de aprofundamento.

Responderam ao teste de evocação 51 professores, dos quais $66,7 \%$ atuam em universidades particulares e $33,3 \%$ em públicas. A maioria é do sexo feminino $(76,5 \%)$ e a idade se concentra na faixa entre 36 e 45 anos (33,3\%). Quanto ao tempo de magistério, 25,5\% estão entre 16 e 20 anos. Todos têm graduação, 52,9\% têm mestrado e 31,5\% doutorado.

Inicialmente, foi solicitado aos professores que escrevessem três palavras que lhes viessem à mente ao ouvir a expressão indutora da formação para o magistério. Em seguida, solicitou-se que as hierarquizassem por ordem de importância, justificando a escolha de cada uma delas por meio de um pequeno texto. As palavras evocadas foram submetidas ao software EVOC (VÉRGES, 1994), que identifica os possíveis elementos do núcleo central considerando a frequência (F) e a ordem 
média (OME). ${ }^{2}$ Os resultados são distribuídos em dois eixos ortogonais, formando quatro quadrantes. O quadrante superior esquerdo, que corresponde ao provável núcleo central $(\mathrm{NC})$, apresenta as palavras de maior frequência e menor OME (ou seja, mais pronta evocação). No quadrante superior direito - a periferia próxima -, encontram-se os elementos com maior frequência e maior OME. No quadrante inferior direito, fica a periferia propriamente dita, onde se localizam os elementos de menor frequência e maior OME. No quadrante inferior esquerdo, encontram-se os elementos de menor frequência e menor OME, denominados elementos de contraste, de mais difícil interpretação, parecendo indicar a existência de subgrupos.

As justificativas para as palavras evocadas, bem como as entrevistas, foram analisadas conforme o proposto por Bardin (1997) para compreender os sentidos atribuídos aos elementos identificados no NC e no sistema periférico. Após essa análise, foram realizadas entrevistas conversacionais com o objetivo de aprofundar a compreensão desses resultados. Dos 15 professores que participaram da entrevista, 9 atuam em universidades públicas e 6 em universidades privadas; 11 são mulheres; 10 têm doutorado e 5 mestrado; 9 se encontram na faixa etária 56 a 70 anos e atuam há mais de 20 anos no magistério.

\section{Resultados}

Os professores que responderam ao teste associaram 153 palavras à expressão formação para o magistério, sendo 108 delas diferentes e apenas 45 iguais, daí as frequências tão pouco expressivas encontradas nos quatro quadrantes. A Tabela 1 apresenta esses resultados.

2 A frequência $(F)$ de uma evocação é o somatório de suas frequências nas diversas posições; a frequência média (FM) é a média aritmética das diversas frequências obtidas por uma evocação. A ordem média de uma evocação (OME) é calculada pela média ponderada obtida mediante a atribuição de pesos diferenciados à ordem com que, em cada caso, uma dada evocação é enunciada. 
Tabela 1 - Possível estrutura da representação social de formação para o magistério para docentes de Pedagogia

\begin{tabular}{llcclcc}
\hline & Palavra evocada & $\mathbf{f}$ & OME $<\mathbf{2 , 1 1}$ & Palavra evocada & $\mathbf{f}$ & OME $\geq \mathbf{2 , 1 1}$ \\
\hline $\mathrm{f} \geq 4$ & Formação & 7 & 1,71 & Atualização & 5 & 2,80 \\
& & & & Pesquisa & 4 & 2,75 \\
\hline $\mathrm{f}<4$ & Amor & 3 & 2,00 & Competência & 3 & 2,67 \\
& Crítica & 3 & 1,67 & Qualidade & 3 & 2,67 \\
& Aluno & 3 & 1,33 & Compromisso & 3 & 2,33 \\
& Desvalorização & 3 & 1,33 & & & \\
\hline
\end{tabular}

A grande dispersão observada nas respostas indica falta de clareza dos professores de cursos de Pedagogia sobre o que é hoje, ou o que deveria ser, a formação de professores, o que também se evidencia na surpreendente redundância encontrada no núcleo central, o que pode ser caracterizado como uma não resposta. Em outras palavras, tais resultados sugerem que esses professores formadores não apresentam uma representação de formação para o magistério.

Procuramos esclarecer essa questão na segunda etapa da pesquisa. Ao perguntar aos entrevistados por que teria a palavra formação aparecido no núcleo da representação de formação para o magistério, eles pareceram confusos, não conseguindo dizer por que seus colegas deram aquela resposta. Alguns tentaram explicá-la dizendo que, provavelmente, os professores entenderam formação para o magistério como sendo a formação inicial, considerada deficiente e distanciada da prática. A repetição da palavra formação teria, então, o sentido de "uma verdadeira formação", mais vinculada à prática. Outros consideram que os professores quiseram destacar a importância da formação pessoal, de sua experiência de vida. As falas abaixo são ilustrativas:

talvez a ideia seja de que a carga maior formativa se dê através da experiência de vida. Porque que eu acho que as pessoas podem pensar isso? Porque 
o curso de formação de professores prepara genericamente para uma realidade, e quando você entra em atividade você termina tendo uma realidade diferente daquela para qual você foi formado. Então o que que conta? Na hora de você "se virar"? Conta a sua própria experiência, já que o seu curso não te preparou para aquela realidade. Isso é uma distorção (P 13).

Não sei por que eles responderam isso. O trabalho deles é formação, não é? Mas... não sei, eu acho que... o seu trabalho como formador de docentes é a sua própria formação .... Não consigo imaginar o que seria. Eu acho que eu responderia a minha formação e o meu trabalho de formar docentes, não é? Não sei (P 7).

Bem, eu vejo que a formação docente, específica pra dar aula, ela se dá através desse esquema que compõe o currículo, não é? Agora, a própria educação que a professora faz é... a vocação que a pessoa tem pra ensinar. Isso é muito importante na profissão docente. Porque na formação de professores você adquire, sim, conhecimentos, não é? Um ou outro professor pode marcar o seu percurso durante a formação, mas ainda vejo a vocação como uma coisa muito importante pro professor, porque você vai lidar com criança, com adolescente, não é? (P 5).

As justificativas apresentadas para a evocação da palavra formação também não ajudam a esclarecer o sentido dessa escolha:

na medida em que leve o aluno à reflexão sobre os saberes constituídos nas diferentes épocas históricas, principalmente a partir da modernidade, deve tornar o espaço escolar um lugar permeado por relações sociais, formando pessoas conscientes e politizadas (P 37).

A formação do professor deve ser tratada com muito carinho e seriedade, como qualquer profissionalização, mas nesta categoria se deve ter mais cuidado, pois o professor trabalhará com diferentes individualidades, com expectativas de vida, demandas sociais e vivências diferentes, principalmente na educação básica (P 41).

Acredito que as escolas de formação ainda não estão preparando o profissional que as camadas populares necessitam. Tanto em nível médio, como no 
nível superior, o professor é preparado para um outro tipo de aluno, diferente do que vai enfrentar na vida profissional, ou seja, no 'chão da escola' (P 30).

Formar professores críticos, conscientes de seu papel (P 48).

Os elementos atualização, pesquisa, competência, qualidade e compromisso, que constituem o sistema periférico, parecem apontar para o que falta na formação, ou o que ela não é, como indicam as justificativas para a associação daqueles termos com o estímulo formação:

não há como exercer o papel de professor sem estar se atualizando dia a dia, principalmente devido às exigências que a atividade hoje requer. Não podemos esquecer que o exercício profissional exige o olhar de pesquisador para buscar as soluções necessárias aos problemas emergentes (P 23).

Deve conhecer a realidade brasileira para problematizar a educação e assim poder pesquisar, não necessariamente de forma acadêmica, mas reflexiva (P 49).

Um curso de competência social/humanizadora, que vá levar o aluno a pensar, a pesquisar e a construir os seus conhecimentos enquanto sujeitos da aprendizagem (P 37).

Os cursos têm que ter qualidade para que, consequentemente, sejam formados melhores professores (P 35).

A escolha de vida profissional no magistério exige compromisso com as camadas populares, despir-se de preconceitos de qualquer ordem e ter como meta principal trabalhar a aprendizagem dos alunos, há, portanto, um envolvimento emocional na atividade (P 30).

Termos comumente encontrados na literatura educacional - como 'professor crítico', 'professor reflexivo', 'professor pesquisador' - presentes nas justificativas, se repetem em inúmeras entrevistas, usados aparentemente sem muito rigor. A apresentação um tanto alongada dessas falas tem por objetivo evidenciar o uso exaustivo dessas expressões com diferentes significados: 
[O professor] deve conhecer a realidade brasileira para problematizar a educação e assim poder pesquisar, não necessariamente de forma acadêmica, mas reflexiva (P 49).

O ser crítico nesta sociedade globalizada é fundamental para a formação de educadores questionadores. Consumimos, a todo momento, uma carga enorme de informações sem a devida preocupação acerca da origem desses materiais (P 8).

Penso que hoje os cursos de formação, quer continuada, quer inicial, devem objetivar a formação de um professor reflexivo, capaz de pensar sobre o seu fazer, seu saber e redirecioná-lo, reconstruí-lo (P 17).

O cotidiano educacional é único e não se repete, mas serve de espaço para que a nossa reflexão aconteça para podermos agir no amanhã de acordo com as necessidades que se apresentem (P 12).

A figura do professor como agente ativo, reflexivo, é central nesse curso/ processo de formação. Importa a concepção de professor que se quer formar nesses cursos (P 25).

O educador pesquisador irá refletir nos educandos esse comprometimento com a busca do conhecimento, tendo em vista que vivemos em constante mudança. Contudo não se deve aceitar preestabelecido e sim formular seu próprio conceito perante a sociedade (P 33).

Ação não vale mais que a reflexão. São pares dialéticos. Agir, praticar e exercitar são imprescindíveis, mas não na perspectiva de um ativismo puro e simples. A reflexão sobre a ação pode propiciar a visão sobre onde quer se chegar, que sujeitos quer se formar, para que projeto de vida e de sociedade se está contribuindo (P 9).

O professor reflexivo é aquele que leve o aluno a ler e a interpretar o mundo de maneira crítica, para a conquista da cidadania plena (P 37).

A expressão 'professor reflexivo', onipresente nas falas de professores, foi popularizada na literatura educacional a partir dos anos 1990, 
por ocasião das discussões sobre reformas curriculares, propostas com base em autores ligados à perspectiva dos "saberes docentes", que, como vimos, valorizam a prática profissional como momento de construção do conhecimento por meio da reflexão, análise e problematização dessa prática. Schön (1995, p. 60) resume essa posição ao afirmar que ensinar é "uma profissão em que a própria prática conduz necessariamente à criação de conhecimento específico e ligado à ação, que só pode ser adquirido pelo contato com a prática, pois se trata de um conhecimento tácito, pessoal e não sistemático".

Embora a ênfase atribuída à reflexividade nos cursos de formação pareça contribuir significativamente para sua presença no discurso dos professores, isso não pode ser tomado como evidência da compreensão da complexidade do processo e de suas implicações políticas e práticas. Na verdade, seu uso reiterado em diferentes contextos discursivos sugere que o termo esteja sendo reduzido a um jargão. Pimenta (2002) já havia observado que o conceito de professor reflexivo estava se transformando em objeto de mera retórica, um simples termo apropriado pelas políticas neoliberais para justificar o aligeiramento da formação.

Apesar da ênfase na idéia do professor-reflexivo, a queixa sobre a dicotomia entre teoria e prática continua em foco, ora criticando o excesso de técnica, ora o excesso de teoria:

a técnica, para muitas pessoas que passam pelo curso de formação para o magistério, é colocada à frente de outras dimensões do processo educativo, ou essas outras dimensões são incorporadas apenas como técnica. Por exemplo, afetividade, subjetividade, respeito ao outro, etc. (P 14).

Infelizmente, a tradição do ensino de conhecimentos teóricos em detrimento da prática invade a formação de professores nos cursos de Pedagogia. Para nós professores cabe o grande desafio: articular teoria e prática. Fazer com que os nossos alunos sejam capazes, a partir dos conhecimentos teóricos, de compreender o cotidiano escolar de forma mais apropriada, para que nele possam intervir (P 17). 
A insistência na dicotomia teoria versus prática parece revelar uma adesão, ainda que inconsciente, ao modelo da racionalidade técnica, que carrega a suposição de que as teorias e técnicas obtidas na formação deveriam ser capazes de dar conta das situações concretas do cotidiano escolar, desconsiderando que é justamente a crítica a esse modelo que está na base dos movimentos que enfatizam a reflexividade. Essa contradição parece poder ser explicada pela observação de Krahe e Wielewicki (2008, p. 133), segundo os quais

diante do movimento de reformas curriculares e das políticas de inovação curricular, observamos que as instituições de ensino superior (IES) freqüentemente externam um alinhamento com propostas curriculares embasadas no que podemos denominar de racionalidade prático/reflexiva de formação de professores, mas operam numa lógica fortemente arraigada nos pilares de uma racionalidade técnico/ instrumental.

Concluindo, na análise do corpus da pesquisa vislumbra-se apenas um consenso: a formação, tal como está, não pode continuar. As falas a seguir são ilustrativas.

A qualidade da educação em geral tem sido comprometida por políticas educacionais equivocadas. Neste contexto, o curso de formação de professores, embora haja grande movimento para mudar esse quadro, não tem conseguido oferecer formação profissional à altura dos desafios que a profissão encerra. Diante de outros cursos superiores, antenados com as transformações econômicas, tecnológicas e culturais recentes, apesar de um discurso muito progressista, tem se estruturado a partir de modelos curriculares ultrapassados (P 40).

Não há possibilidades de se conceber a formação docente sem inscrever suas ações no âmbito das ações políticas mais amplas. A preocupação com a formação inicial e continuada vem se tornando um tema incontornável das ações de políticas educacionais (P 26). 


\section{Considerações finais}

$\mathrm{Na}$ análise da possível estrutura da representação social de formação para o magistério, elaborada por professores de curso de Pedagogia, a dispersão refletida nos inexpressivos resultados referentes aos termos evocados, em especial o que corresponderia ao núcleo central (sete evocações da palavra formação em 153), nos levou a questionar a existência de uma representação de formação para o magistério, parecendo que esses professores têm apenas opiniões, ou mesmo atitudes, mas não uma representação estruturada.

Tais resultados foram confirmados nas entrevistas, pois ao serem indagados sobre por que a palavra formação teria sido a mais frequentemente associada ao estímulo formação para o magistério, na primeira fase da pesquisa, os professores deram respostas confusas, não conseguindo explicar a razão daquela resposta. Contudo, o que é mais preocupante, não conseguiram eles próprios apresentar uma representação consistente, formulando um discurso fragmentado, pontilhado por expressões e noções retiradas da literatura corrente, sem, contudo, conseguir costurar uma imagem coerente do objeto formação para o magistério.

É possível afirmar que a existência de duas racionalidades em disputa, tanto nas discussões relativas às Diretrizes Curriculares para o curso de Pedagogia como na literatura sobre formação do professor, tenha contribuído significativamente para os resultados obtidos nas respostas ao teste de associação e nas entrevistas. A mudança de paradigma proposta pela legislação implica mudanças profundas na concepção de formação de professores, cujos desdobramentos em termos de conteúdos e de atividades a serem oferecidas aos futuros professores são ainda objeto de grandes controvérsias, não tendo sido, como assinalam Gatti e Barretto (2009), devidamente assimiladas pelas próprias instituições formadoras.

Não causa surpresa, portanto, que o discurso dos professores sobre a formação e os saberes da docência se revele tão pontuado por clichês, tão confuso e até mesmo contraditório. Isto não quer dizer que esses dados não sejam preocupantes, pois, considerando que as representações 
são "condição das práticas", é válido concluir que esses docentes dificilmente serão capazes de oferecer, aos professores da educação infantil e das primeiras séries do ensino fundamental, uma formação que os ajude a dar o salto qualitativo necessário à melhoria desses níveis de ensino.

Concluindo, a questão da formação dos professores continua sendo um grande desafio para as políticas governamentais, as instituições formadoras e também para seus professores. Segundo Gatti (2009), dados obtidos em inúmeros estudos, bem como em avaliações nacionais, regionais e locais do desempenho dos sistemas de ensino, mostram um cenário nada animador. Nesse sentido, uma última questão se impõe. Considerando que: a) formar docentes para as instituições de ensino superior é um dos objetivos dos programas de pós-graduação; b) 84,4\% dos participantes da primeira fase da pesquisa fizeram pós-graduação (52,9\% têm mestrado e $31,5 \%$ doutorado), assim como $100 \%$ dos que participaram das entrevistas (cinco com mestrado e dez com doutorado); é urgente que nós, docentes desses programas, procuremos nos perguntar o que podemos fazer para ajudar nossos alunos a refletirem sobre o papel do formador de novos docentes para a escola básica, um papel que a grande maioria deles ou já exerce ou exercerá no futuro.

\section{Referências}

ABRIC, J. C. Représentations sociales: aspects théoriques. In: ABRIC, J. C. (Org.). Pratiques sociales et représentations. Paris: Presses Universitaires de France, 1994.

ABRIC, J. C. A abordagem estrutural das representações sociais. In: MOREIRA, A. S. P.; OLIVEIRA, D. C. (Org.). Estudos interdisciplinares em representações sociais. Goiânia: AB Editora, 1998. p. 27-38.

ABRIC, J. C. Abordagem estrutural das representações sociais: desenvolvimentos recentes. In: CAMPOS, P. H. F.; LOUREIRO, M. C. S. (Org.). Representações sociais e práticas educativas. Goiânia: Ed. da UCG, 2003. p. 37-57. 
AGUIAR, M. A. S. et al. Diretrizes curriculares do curso de pedagogia no Brasil: disputas de projetos no campo da formação do profissional da educação. Educação \& Sociedade, Campinas, v. 27, n. 96, p. 819-842, 2006.

AGUIAR, M. A. S.; SHEIBE, L. Formação e valorização. Desafios para o PNE 2011/2020. Revista Retratos da Escola, Brasília, v. 4, n. 6, p. 77-90, 2010.

ALVES-MAZZOTTI, A. J. Um estudo sobre os processos formadores das representações sociais de "ser professor". In: ENCONTRO NACIONAL DE DIDÁTICA E PRÁTICA DE ENSINO, 14., 2008, Porto Alegre. Anais... Porto Alegre: ENDIPE, 2008. CD-ROM.

ALVES, W. F. A formação de professores e as teorias do saber docente: contextos, dúvidas e desafios. Educação e Pesquisa, v. 33, n. 2, p. 263-280, 2007.

BARDIN, L. Análise de conteúdo. Porto: Edições 70, 1997.

BORGES, C.; TARDIF, M. Apresentação do dossiê "Os saberes dos docentes e sua formação”. Educação \& Sociedade, Campinas, v. 22, n. 74, p. 11-26, 2001.

BRASIL. Lei n. 9.394/96, de 20 de dezembro de 1996. Estabelece as diretrizes e bases da educação nacional. Diário Oficial [da] República Federativa do Brasil, Poder Legislativo, Brasília, DF, 23 dez. 1996. p. 27833. Disponível em:<http:// www6.senado.gov.br/legislacao/ListaTextoIntegral.action?id=75723>. Acesso em: 23 jul. 2009.

DIAS-DA-SILVA, M. H. G. F. Política de formação de professores no Brasil: as ciladas da reestruturação das licenciaturas. Perspectiva, Florianópolis, v. 23, n. 2, p. 381-406, 2005.

FREITAS, H. C. L. Formação de professores no Brasil: 10 anos de embate entre projetos de formação. Educação \& Sociedade, Campinas, v. 23, n. 80, p. 137-168, 2002.

GATTI, A. B. Formação de professores: condições e problemas atuais. Revista Brasileira de Formação de Professores, v. 1, n. 1, p. 90-102, 2009.

GATTI, A. B.; BARRETTO, E. S. Professores do Brasil: impasses e desafios. Brasília: Unesco, 2009. 
GUIMARÃES, V. S. Formação de professores: saberes, identidade e profissão. Campinas: Papirus, 2010.

KRAHE, E. D.; WIELEWICKI, H. G. Formação docente, pedagogia universitária e mudanças de racionalidade: contribuições ao debate sobre políticas educativas. In: ENCONTRO INTERNACIONAL DE PESQUISADORES DE POLITICAS EDUCATIVAS, 3., 2008, Porto Alegre. Anais... Porto Alegre: UFRGS/FACED/ Núcleo de Estudos de Política e Gestão da Educação, 2008. p. 133-138.

JODELET, D. Representações sociais: um domínio em expansão. In: JODELET, D. (Org.). Representações sociais. Rio de Janeiro: EDUERJ, 2001. p. 17-44.

MOSCOVICI, S. A representação social da psicanálise. Rio de Janeiro, Zahar, 1978.

PIMENTA, S. G. Professor reflexivo: construindo uma crítica. In: PIMENTA, S. G; GHEDIN, E. (Org.). Professor reflexivo no Brasil: gênese e crítica de um conceito. São Paulo: Cortez, 2002. p. 17-52.

SCHÖN, D. A. Formar professores como profissionais reflexivos. In: NÓVOA, A. (Coord.). Os professores e a sua formação. Lisboa: Dom Quixote, 1995. p. 77-91. VERGÈS, P. Approche du noyau central: propriétés quantitatives et structurales. In: GUIMELLI, C. (Ed.). Structures et transformations des représentations sociales. Neuchâtel: Delachaux et Niestlé, 1994. p. 233-253.

Recebido: 23/12/2010

Received: 12/23/2010

Aprovado: 15/02/2011

Approved: 02/15/2011 